\title{
NCEP Reanalysis and Precipitation Isotopes to Discuss Water Vapor Source in Baotou
}

\author{
Xie Fei ${ }^{1,2 a}$, Yu Yan-ling2, Qin Xiang-nan ${ }^{2}$ \\ ${ }^{1}$ Pingliang Monitoring Sub-station of Soil and Water Conservation, Pingliang 744000, China \\ ${ }^{2}$ College of Water Conservancy and Hydropower Engineering, Hohai University, Nanjing 210098 , \\ China
}

a18252502@qq.com

\begin{abstract}
Keywords: Stable Isotope; Precipitation; Backwards Trajectory; Reanalysis Data
Abstract. By dint of isotope data of the atmospheric precipitation and NCEP reanalysis data, the changes characteristics of precipitation in Baotou were analyzed. It showed a positive correlation between the weighted average of $\delta 18 \mathrm{O}$ and precipitation, which was related to the semi-arid climate of Baotou. The slope and intercept of local meteorological water line (LMWL) of Baotou were lower than that of Global Meteorological Water Line (GMWL). Combined environmental stable isotope data of precipitation with Backwards Trajectory model, it showed: 1) Baotou was dominated by westerly continental vapor throughout the year, and also was influenced by the oceanic vapor in spring and summer. 2) Owing to the high temperature, Baotou was remarkably effected by local evaporation of water vapor in spring and summer.
\end{abstract}

\section{Introduction}

The application of environmental isotopes $(18 \mathrm{O}, 2 \mathrm{H})$ method is valuable to the study of water environment and isotopes hydrology [1], and its application in the research of precipitation began in the early 1950s [2].Researches have shown that stable isotopes composition in precipitation and their value depends on the the initial state of the source area and the transport process of water vapor [3], and differs from other factors of the study area, such as the temperature, humidity, altitude, latitude and longitude etc. In 1961, the International Atomic Energy Agency (IAEA) and the World Meteorological Organization (WMO) jointly initiated and established the Global Network of Isotopes in Precipitation (GNIP), in order to provide the basic data to determine the global or regional water cycle mechanism[4]. Due to the lack of observation data, the traditional pattern of water vapor transport process research is limited to some extent, but it shows great superiority to apply the environmental isotopes technology combined with atmospheric circulation patterns for water vapor transport process research[5,6]. This paper utilized the hydrogen and oxygen isotopes data and the water vapor path data from the backward trajectory method of Baotou, the hinterland of north China, to make a qualitative evaluation of contribution of precipitation by different source of water vapor, which can provide scientific basis to understand and grasp the regional hydrologic cycle process and protect and utilize the water resources reasonably.

\section{Engineering Background}

Baotou is located in the north of China (Fig. 1), the scope of its geographic coordinates to $41^{\circ} 20^{\prime} \sim$ $42^{\circ} 40^{\prime} \mathrm{N}, 109^{\circ} 50^{\prime} \sim 111^{\circ} 25^{\prime} \mathrm{E}$. Within the territory of the Yinshan Mountains across the middle, and it is a natural barrier block detaining northern cold air. Generally, the middle is high and the north and south is low in terrain, and its average altitude is $1100 \sim 2000 \mathrm{~m}$. Baotou belongs to the temperate semi-arid climate zone, with typical continental climate characteristics, whose winter is long and cold and summer is short and sunny. Its Years of average rainfall is $254.9 \mathrm{~mm}$, and dryness is $1.52-2.76$.

The data of Baotou Precipitation isotopes $(18 \mathrm{O}, 2 \mathrm{H})$ is referred from the Global Network of Isotopes in Precipitation (GNIP ). The station is located in $109.85^{\circ} \mathrm{E}, 40.67^{\circ} \mathrm{N}$, and the monitoring times were $1986 \sim 1993$. Each observation point in the network project includes items such as 
the $\delta \mathrm{D}, \delta 18 \mathrm{O}, 3 \mathrm{H}$, temperature and precipitation, and the data recording time was 15 th of every month, so the stable isotopes ratio of months can represent the average, from the 16th last month to the 15th of this month.

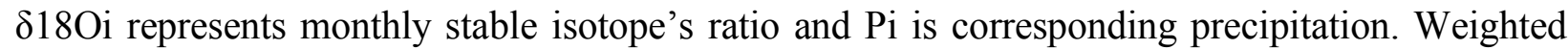
monthly average values of isotopes in precipitation for Baotou showed in Table 1.

Table 1. Weighted monthly average values of isotopes in precipitation for baotou

\begin{tabular}{cccc}
\hline Mouth & $\mathbf{\delta D} / \% \mathbf{0}$ & $\mathbf{\delta}^{\mathbf{1 8}} \mathbf{O} / \mathbf{\%}$ & Precipitation/mm \\
\hline Jan & -138.64 & -19.65 & 2.17 \\
Feb & -71.76 & -10.06 & 5.00 \\
Mar & -69.21 & -10.99 & 13.33 \\
Apr & -42.86 & -6.56 & 9.33 \\
May & -43.11 & -5.46 & 17.83 \\
Jun & -43.63 & -6.03 & 33.17 \\
Jul & -61.94 & -8.13 & 66.00 \\
Aug & -54.77 & -7.90 & 77.83 \\
Sep & -47.83 & -7.08 & 35.50 \\
Oct & -68.99 & -10.05 & 16.33 \\
Nov & -71.28 & -9.92 & 2.50 \\
Dce & -69.60 & -11.07 & 4.67 \\
\hline
\end{tabular}

\section{Water Vapor Sources and ItsRelationship With The $\boldsymbol{\delta} 180$}

The water vapor sources and its relationship with the $\delta 180$ of Baotou were analyzed with the hydrogen and oxygen isotopes as a natural tracer, combined with the Backwards Trajectory. In mainland of China ,it could be divided into the spring (March to May), summer (June to August), autumn (September to December) and winter (November to February of the next year).

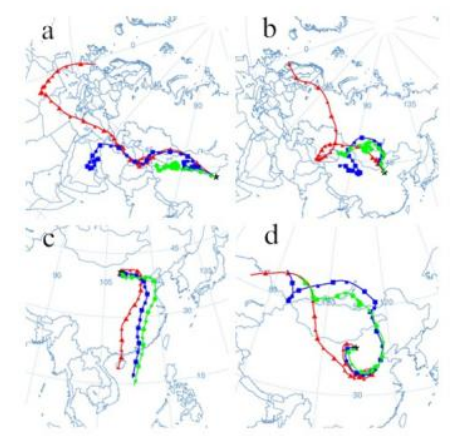

Note: a, Winter; b, Spring; c, Summer; d, Autumn

Fig. 1 The trajectory of water vapor in different seasons

The value of $\delta 180$ is low in autumn and winter, and the water vapor is mainly from the Atlantic Ocean and Asian northern areas, according to the Backwards Trajectory. The vapor flow, containing water from the Atlantic ocean, went through the Middle East and central Asia, then into Mongolia Plateau and finally arrived in Baotou (Fig. 1 a). At autumn time, westerlies continental water vapor took advantage in air mass, mainly from Kazakhstan, Mongolia Plateau and other Asian northern areas (Fig. $1 \mathrm{~d}$ ). Water vapor of the westerlies dominated in this period, and the water vapor transport over long distance resulted in the dilution of stable isotopes in water vapor. Precipitation in fall and winter rainfall was less mainly because of the poor condition of the water vapor of the westerlies.

\section{Relationship Between $\delta 180$ And Precipitation}

Precipitation amount effect refers to that the value of $\delta \mathrm{D}$ and $\delta 18 \mathrm{O}$ and the amount of precipitation showed the inverse correlation. Due to the low humidity of the air in arid and semi-arid 
regions, the raindrops were likely to be affected by evaporation before they reach the ground in the process of rainfall, leading to the isotopes fractionation effect. Therefore, there are usually precipitation effect in $\delta 180$. But there is no rainfall effect in Baotou area .The weighted monthly average of $\delta 180$ and precipitation were positively correlated, namely the rainfall, the greater the $\delta 180$ value, the greater (Fig. 2).

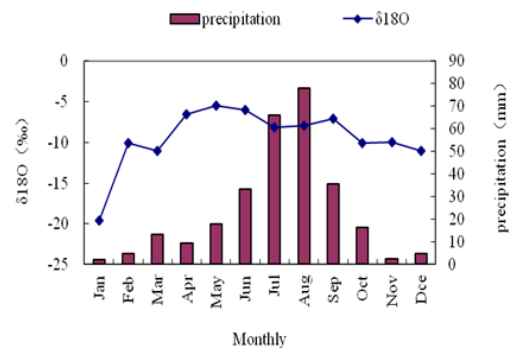

Fig. 2 The correlation of $\delta 18 \mathrm{O}$ ( Weighted mean) with monthly average precipitation

The reasons may be as follows: 1) precipitation of Baotou mainly concentrated in April to October, during which the temperature is also higher, and the higher temperature led to evaporation in the process of precipitation, which caused isotopes fractionation effect, making the $\delta$ value of isotopes still high even with high rainfall; 2) with less rainfall in autumn and winter, the temperature is low, and heavy isotopes dilution happened. Moreover, cold season precipitation is more solid, it is not easy for precipitation to evaporate in cold season, so that the $\delta$ value of isotopes low with small rainfall. 3 ) the $\delta$ value of stable isotopes in precipitation is related to the water vapor sources to some extent. The $\delta 180$ value in the water vapor from the arctic ocean in high latitudes is low, while it is higher in water vapor from the Atlantic ocean - the Mediterranean westerlies, but as a result of long-distance transport, the stable isotopes dilution of water vapor happened gradually; in spring and autumn, water vapor from Kazakhstan, Mongolia plateau and other north Asian continent account for large proportions. Continental moisture stable isotopes ratio is higher, with water vapor of local secondary evaporation with stable isotopes enrichment to join, made $\delta 18 \mathrm{O}$ in atmospheric precipitation on the high side eventually.

\section{The Changes Of The $\delta D$ And $\delta 180$ In Precipitation}

The relationship between the $\delta \mathrm{D}$ and $\delta 18 \mathrm{O}$ in atmospheric precipitation is of great significance to the study of the change of stable isotopes in the process of water circulation. The slope of the relationship line between hydrogen and oxygen isotope in precipitation is higher influenced by continental atmospheric water vapor sources, but lower influenced by oceanic water vapor sources [10]. By Figure 3, there are significant differences in the linear relations between the $\delta \mathrm{D}$ and $\delta 18 \mathrm{O}$ in atmospheric precipitation of Baotou, and the slope in fall and winter is inferior to that in spring and summer. According to data of the Backwards Trajectory, it was found that: 1) the influence of continental atmospheric water vapor source of the water cycle on precipitation is stronger in fall and winter than that in spring and summer, and the water vapor of local evaporation occupy the bigger proportion; 2) the influence of the oceanic water vapor is frequent in spring and summer.

Compared with the Global Meteoric Water Line (GMWL) $\delta D=8 \delta^{18} O+10$ (Fig. 4), first proposed by Craig, the slope and intercept of this equation are on the low side. The main reason is that Baotou is far away from the ocean and the climate there is very arid, and there is a big part of the water vapor coming from local evaporation. The $\delta 18 \mathrm{O}$ and $\delta \mathrm{D}$ in the surface water in arid regions are on the high side, so $\delta 18 \mathrm{O}$ and $\delta \mathrm{D}$ in the evaporation moisture is on the high side accordingly; at the same time, under arid climate conditions, the enrichment of the heavy isotopes, generated by evaporation during the raindrops falling down, is another reason. 


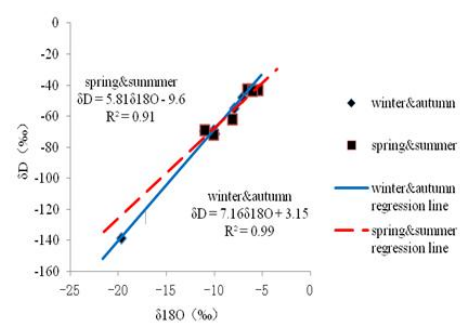

Fig. 3 Relationship between $\delta 180$ and $\delta \mathrm{D}$

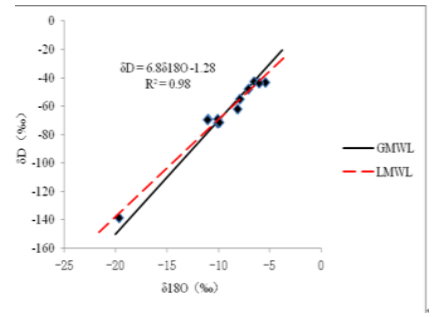

Fig.4 Local meteoric water line in Baotou

\section{Conclusions}

(1) Baotou is mainly controlled by the westerlies activities. In autumn and winter, the influence of westerlies continental local water vapor sources is higher; the westerlies continental water vapor still takes advantage position in spring and summer, under the influence of oceanic water vapor at the same time. Due to the higher temperature, local evaporation of water vapor is quite obvious.

(2) The weighted monthly average of $\delta 180$ in Baotou precipitation and the amount of precipitation were positively correlated.

(3) The local atmospheric precipitation line equation in Baotou is $\delta D=7.92 \delta^{18} O+4.24$, and its slope and intercept are low, compared with the Global Meteoric Water Line (GMWL), which has a certain relationship with the arid climate of Baotou. In arid regions, $\delta 180$ and $\delta \mathrm{D}$ in surface water is on the high side, so the $\delta 18 \mathrm{O}$ and $\delta \mathrm{D}$ in evaporated water vapor is also on the high side; at the same time, due to the heavy isotopes enrichment made by evaporation, $\delta 18 \mathrm{O}$ in precipitation in spring and summer of Baotou is high.

\section{References}

[1]Dansgaard W. The abundance of 180 in atmosphere water and water vapor $[\mathrm{J}]$. Tellus, 1953, 5: 461-469.

[2]Clark I D, Fritz P. Environmental Isotopes in Hydrogeology [M] . Boca Raton, FL: Lewis Publishers, 1997: 328.

[3]Rozanski K, Araguas L, Gonfiantini R, Relation between long-term trends of oxygen-18 isotope composition of precipitation and climate $[\mathrm{J}]$.Science, 1992, 258: 981 -985.

[4]Salati E., Dall Olio A, Matsui E., Recycling of water in the Amazon basin; an isotopic study (J) . Water Resources Research, 1979, 15(5):1250 -1258.

[5]Rozansky K., C. Sontag, K. O. Munich., Factors controlling stable isotope composition of European precipitation $〔 \mathrm{~J} 〕$. Tellus, 1982, 34(2):142 -150.

[6]Yuan Bo-guo, Wang Jian-Jun, Zhang Feng-mei, Analysis climate characteristics in Baotou, [J] . Meteorology Journal of Inner Mongolia, 2007, 4: 21-23. 